\title{
Assessment of Serum Level of SIRT1 in Patients with Acne Vulgaris
} N.E.Sorour ${ }^{1}$, A.M.Hamed ${ }^{1}$, A.A.Elfallah ${ }^{1}$ and D.M.Eid $^{2}$

${ }^{1}$ Dermatology, Venereology and Andrology Dept., Faculty of Medicine, Benha Univ., Benha, Egypt ${ }^{2}$ Dermatology, Venereology and Andrology, Zagazig Univ., Zagazig, Egypt

E-Mail: dina.3m.e@ hotmail.com

\begin{abstract}
Four elements are accepted to assume a key function in the improvement of skin break out sores: abundance sebum creation, upset keratinization inside the follicle, colonization of the pilosebaceous conduit by Propionibacterium acnes, and the arrival of incendiary middle people into the skin. Point: Evaluation of serum levels of sirtuin1 (SIRT1) in skin inflammation vulgaris patients. Patients and Methods: Serum SIRT1 focuses were estimated in 30 patients with AV and 15 solid controls utilizing chemical connected immunosorbent examine (ELISA). Results: Serum SIRT1 levels are diminished in patients with serious AV contrasted with patients with gentle, moderate and controls. End: Decreased serum SIRT1 presumably mirror the part of SIRT1 in the pathogenesis of AV.
\end{abstract}

Keywords: Acne vulgaris, SIRT1, ELISA.

\section{Introduction}

Skin break out vulgaris (AV) is a typical ceaseless incendiary skin illness of the pilosebacous units influencing teenagers focusing all over, chest and back and portrayed by arrangement of open and shut comedones, erythrematous papules, pustules and less regularly by knobs or pseudocyst [1].

Skin break out pathogenesis is multifactorial with 4 essential factors that assume a crucial part in the development of skin break out injuries: overabundance sebum creation, strange keratinization, irritation, and bacterial colonization of Propionibacterium acnes in the pilosebaceous unit. Aggravation has for quite some time been perceived as significant factor in the pathogenesis of skin inflammation; in any case, as of not long ago it was viewed as an auxiliary occasion. Studies over the previous decade have exhibited a focal part for irritation in the improvement of skin break out sores and have opened new open doors for helpful mediation [2].

The sebaceous organ is a skin member that communicates numerous receptors, including Toll-Like Receptors (TLRs). TLR-2 is communicated in keratinocytes, sebocytes, dendritic and inflammatory cells, just as in monocytes and macrophages in skin break out patients. It assumes an essential function in comedogenesis and inflammation by means of actuation of transcriptional atomic variables, for example, NF-к $\beta$, through setting off the creation of a few cytokines (counting IL-1 , IL-8, IL-12) and by means of initiation of different cells, for example, macrophages, common executioner (NK) and neutrophils [3].

Acetylation of proteins, happening during cell digestion, assumes a significant part in the guideline of the post-translational adjustment and record instrument which is constrained by histone acetyltransferase and deacetyltransferases [4]. There are 18 sorts of histone deacetylases, of which 11 are zinc-needy and 7 are nicotinamide adenine dinucleotide (NAD)- subordinate. NAD-subordinate histone protein deacetylases comprise the sirtuin gathering, which incorporates 7 kinds of deacetylases. Sirtuin 1 is a NAD-dependant class III protein deacetylase [5].
SIRT1 assumes a significant part in cell measures, including quality articulation, cell cycle guideline, cell digestion, oxidative pressure reaction, apoptosis, DNA fix and maturing [6]. Sirtuin 1 is likewise connected with aggravation and resistant reaction [7].

The function of sirtuins in fiery skin infection is perplexing and research is in its beginning phases. Momentum research underpins the part of sirtuins in aggravation basically through tweak of the NF-к $\beta$ protein complex [8].

So diminished degree of SIRT1 may assume a part in the pathogenesis of skin inflammation vulgaris, The point of this investigation is to assess the function of SIRT1 in skin break out vulgaris.

\section{Material and methods}

This close to case control study included 30 patients with skin break out vulgaris and 15 sound, age and sex facilitated controls heading off to the dermatology outpatient office at Benha University Hospital, Benha, Egypt from November 2018 to May 2019. Individuals gave their informed created consent before enrolment and the assessment was supported by the Research Ethics Committee in Faculty of Medicine, Benha University.

\subsection{History taking}

Patients' demographic data were recorded: name, age and marital status. A detailed history was taken from patients regarding onset, course, duration and recurrence of acne. Ask about medical problems including any systemic or skin diseases or drug intake.

\subsection{Clinical examination}

Complete general examination was done including body mass index.

Full general examination to exclude associated systemic diseases such as diabetes mellitus, and other inflammatory diseases, Detailed dermatological examination; to evaluate clinical variant, severity of AV and presence of acne scars. 


\section{3 blood samples}

Blood samples were obtained and samples were allowed to clot for 30 minutes at room temperature before centrifugation for 10 minutes at $10000 x y$. The resultant serum was aliquoted and stored at $-20{ }^{\circ} \mathrm{C}$. we avoided repeated freeze-thaw cycles. After centrifugation, serum was separated by a pipette, divided and kept in eppendorf tubes labeled with the number of the person.

This test was done using Human sirtuin 1 ELISA Kit provided by Bioassay Technology Laboratory (Shanghai-China) according to the manufacturer's instructions.

\subsection{Statistical analysis}

The collected data were tabulated and analyzed using SPSS version 16 soft ware (SpssInc, Chicago, ILL Company).

\section{Results and discussion \\ 3.1 Laboratory results}

The current study was carried out on 30 patients with acne vulgaris. The control group included 15 healthy subjects.

There was a statistically significant decrease in the mean serum level of SIRT1 in severe acne patients in comparison to mild, moderate and controls Table (1).

Table (1) Comparison between patient with different severity grades of acne and controls regarding serum SIRT1 level.

\begin{tabular}{|c|c|c|c|c|c|c|}
\hline \multirow[t]{2}{*}{ Grade } & \multirow[t]{2}{*}{ N. } & \multicolumn{2}{|c|}{ Serum SIRT1 (ng/ml) } & \multirow{2}{*}{$\begin{array}{l}\text { KW } \\
\text { test }\end{array}$} & \multirow[t]{2}{*}{$\mathbf{P}$} & \multirow[t]{2}{*}{ Multiple comp (P) } \\
\hline & & Median & IQ Range & & & \\
\hline \multirow{3}{*}{$\begin{array}{l}\text { Controls } \\
\text { Mild } \\
\text { Moderate }\end{array}$} & 15 & 2.22 & $1.32-3.5$ & \multirow[b]{3}{*}{8.45} & \multirow{3}{*}{$<0.05$} & control $\neq$ mild $(0.12)$ \\
\hline & 10 & 2.01 & $1.62-2.99$ & & & control $\neq \bmod (1.0)$ \\
\hline & 10 & 1.90 & $1.55-2.80$ & & & $\begin{array}{c}\text { control } \neq \text { severe } \\
(0.004)\end{array}$ \\
\hline \multirow[t]{2}{*}{ Severe } & & & & & & $\operatorname{mild} \neq \bmod (1.1)$ \\
\hline & 10 & 1.32 & $0.8-1.9$ & & & $\begin{array}{l}\operatorname{mild} \neq \text { severe }(1.2) \\
\bmod \neq \text { severe }(1.2)\end{array}$ \\
\hline
\end{tabular}

\subsection{Discussion}

Skin break out vulgaris is an interminable skin ailment of the pilosebaceous unit and creates because of blockages in the skin's hair follicles. These blockages are thought to happen because of the accompanying four irregular cycles: expanded sebum creation (affected by androgens), unreasonable affidavit of the protein keratin prompting comedo arrangement, colonization of the follicle by Cutibacterium acnes (C. acnes) microscopic organisms, and the neighborhood arrival of ace incendiary synthetic compounds in the skin [9].

The mammalian sirtuins, SIRT1-7, are ensnared in an assortment of cell capacities, running from quality hushing, control of the cell cycle and apoptosis, to vitality homeostasis. SIRT1 is the nearest homolog to Sir2 and the best comprehended as far as cell action and capacity [10].

The point of this work was to gauge serum level of SIRT1 to survey its function in skin inflammation vulgaris and to recognize its relationship with seriousness and movement of the ailment.

This was done through assessment of 30 patients. 15 solid skin inflammation free people were selected as a benchmark group.

As per consequences of the current investigation, there was a measurably critical diminishing in serum SIRT1 level among serious cases contrasted with mellow, moderate and control gathering.

Supposedly, no distributed examinations were found to think about the outcomes between AV patients concerning serum SIRT1 levels.

The consequences of the current examination were identified with the aftereffects of the investigation led by Yang et al. [11]; they exhibited that little particle activators of SIRT1 (STACs) improve deacetylation of cell p65 protein, which brings about the concealment of TNF $\alpha$-incited NF-к $\beta$ transcriptional initiation and decrease of LPS-animated TNF $\alpha$ emission in a SIRT1subordinate way. In an intense mouse model of LPSactuated irritation, the STAC SRTCX1003 diminished the creation of the proinflammatory cytokines TNF $\alpha$ and IL-12. Thier examines demonstrate that expanding SIRT1-intervened NF-к $\beta$ deacetylation utilizing little particle actuating mixes is a novel way to deal with the advancement of another class of helpful mitigating operators.

As AV is considered as one of the fiery sicknesses [12], the consequences of this examination come in concurrence with comparable investigations performed on other provocative illnesses that affirm this idea. For instance, these outcome concurred with the examination led by Rasheed et al. [13]; they found that SIRT1 was altogether lower in lesional psoriatic skin with steady increment in perilesional followed by control skin. Additionally Becatti et al. [14] ; found that there is a diminished SIRT1 articulation and movement in lesional psoriatic fibroblasts, recommending the association of SIRT1 in the pathogenesis of psoriasis.

Despite the fact that the part of SIRT1 in irritation is valued, its inclusion in the pathogenesis of skin break out has not been all around clarified. Notwithstanding, a line of proof recommends the pathogenic part of SIRT1 in skin break out. For instance, actuation of record factor $\mathrm{NF}-\kappa \beta$ had been recognized in skin biopsies from patients with $\mathrm{AV}, \mathrm{NF}-\kappa \beta$ is upregulated after $\mathrm{T}$ cell initiation and moved to the core, which prompts proinflammatory cytokine record [3]. 
Reliable with this thought, it isn't astonishing that this examination discovered diminished serum levels of SIRT1 in extreme AV, which is because of the significance of irritation in pathogenesis of AV which likewise could be stifled by SIRT1.

\section{Conclusion}

Taking everything into account, SIRT1 appears to have a fundamental function in the etiopathogenesis of incendiary skin infections including AV. So it is viewed as a promising objective in treating incendiary maladies.

\section{References}

[1] P. Toossi, Z. Azizian, H. Yavari, T.H. Fakhim, S.H.S. Amini and R. Enamzade, Serum 25-hydroxy vitamin D levels in patients with acne vulgaris and its association with disease severity. Clinical Cases in Mineral and Bone Metabolism: The Official Journal of the Italian Society of Osteoporosis, Mineral Metabolism, and Skeletal Diseases, Vol.12(3), PP.238-42, 2015.

[2] LF. Stein Gold, What's new in acne and inflammation. J Drugs Dermatol, Vol.12(6), PP.s67-s69, 2013.

[3] JL. Selway, T. Kurczab, T. Kealey, K. Langlands, Toll-like receptor 2 activation and comedogenesis: implications for the pathogenesis of acne. BMC Dermatology, Vol.13, PP.10, 2013.

[4] T. Ichikawa, R. Hayashi, K. Suzuki, S. Imanishi, K Kambara, S. Okazaw, Sirtuin 1 activator SRT1720 suppresses inflammation in an ovalbumin-induced mouse model of asthma. Respirology, Vol. 18, PP.332-339, 2013.

[5] B. Osborne, GJ. Cooney, N. Turner, Are sirtuindeacetylase enzymes important modulators of mitochondrial energy metabolism? Biochimica et Biophysica Acta, Vol.1840(4), PP.1295-302, 2013.

[6] JT. Rodgers, P. Puigserver, Fasting-dependent glucose and lipid met-abolic response through hepatic sirtuin 1. Proceedings of the National Academy Science of the Unite State of America, Vol.104, PP.12861-12866, 2007.

[7] TT. Schug, Q. Xu, H. Gao, A. Peres-da-Silva, DW. Draper, MB. Fessler, Myeloid deletion of SIRT1 induces inflammatory signaling in response to environmental stress. Molecular and Cellular Biology, Vol.30, PP.4712-4721, 2010.

[8] T. Kawahara, E. Michishita, A. Adler, M. Damian , E. Berber, SIRT6 links histone H3 lysine 9 deacetylation to NF- kappaB-dependent gene expression and organismal life span. Cell, Vol.136, PP.62-74, 2009.

[9] T. Simonart, Immunotherapy for acne vulgaris: current status and future directions. American Journal of Clinical Dermatology, Vol.14(6), PP.429-35, 2013.

[10] MC. Haigis, LP. Guarente, Mammalian sirtuins: emerging roles in physiology, aging, and calorie restriction. Genes Dev, Vol.20, PP.2913-2921, 2006.

[11] H. Yang, W. Zhang, H. Pan, HG. Feldser, E. Lainez, C. Miller, SIRT1 Activators Suppress Inflammatory Responses through Promotion of p65 Deacetylation and Inhibition of NF-kB Activity. PLoS ONE, Vol.7(9), PP.e46364, 2012.

[12] MA. Rocha, E. Bagatin, Skin barrier microbiome in acne. Arch Dermatol Res, Vol.310(3), PP.181-185, 2018.

[13] H. Rasheed, MHM. El-Komy, RA. Hegazy, HI. Gawdat, AM. AlOrbani and OG Shaker, Expression of sirtuins 1, 6, tumor necrosis factor, and interferon- $\gamma$ in psoriatic patients.International Journal of Immunopathology and Pharmacology, Vol.29(4), PP. 764-768, 2016.

[14] M. Becatti, V. Barygina, G. Emmi, E. Silvestri, N. Taddei, T. Lotti and C. Fiorillo, SIRT1 activity is decreased in lesional psoriatic skin. Intern Emerg Med, Vol.11(6), PP.891-3, 2016. 